\title{
Electrical breakdown and chemical properties of polypropylene/calcium carbonate nanocomposites
}

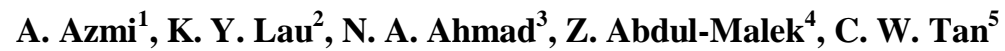 \\ 1,2,3,4 Institute of High Voltage and High Current, School of Electrical Engineering, Universiti Teknologi Malaysia, Malaysia \\ ${ }^{5}$ Division of Electrical Power Engineering, School of Electrical Engineering, Universiti Teknologi Malaysia, Malaysia
}

\begin{tabular}{l} 
Article Info \\
\hline Article history: \\
Received Feb 2, 2020 \\
Revised Apr 5, 2020 \\
Accepted Apr 19, 2020 \\
\hline Keywords: \\
Breakdown \\
Calcium carbonate \\
Dielectric \\
Nanocomposites \\
Polypropylene
\end{tabular}

Polypropylene

\begin{abstract}
Calcium carbonate $\left(\mathrm{CaCO}_{3}\right)$ is an inorganic material which has been introduced in polymeric insulation to improve the thermal and electrical properties of insulation. In this research, a comparative study was performed between unfilled polypropylene (PP) and PP nanocomposites containing $5 \mathrm{wt} \%$ of $\mathrm{CaCO}_{3}$ nanofiller. The electrical breakdown performances of unfilled PP and nanocomposites were investigated. The chemical content of the material was carried out using Fourier transform infrared (FTIR) spectroscopy. The findings showed that the introduction of $\mathrm{CaCO}_{3}$ to the PP altered the chemical bonding of the material, where two additional characteristic absorption bands appeared in the FTIR spectra of $\mathrm{PP} / \mathrm{CaCO}_{3}$ nanocomposites. In addition, $\mathrm{PP} / \mathrm{CaCO}_{3}$ nanocomposites had slight changes on the AC breakdown strength compared to unfilled PP. Meanwhile, the DC breakdown performance of the nanocomposites was apparently lower than that of unfilled PP. These were attributed to the agglomeration of $\mathrm{CaCO}_{3}$.
\end{abstract}

Copyright () 2020 Institute of Advanced Engineering and Science. All rights reserved.

\section{Corresponding Author:}

Aizat Bin Azmi,

Institute of High Voltage and High Current,

School of Electrical Engineering,

Universiti Teknologi Malaysia,

81310 Johor Bahru, Malaysia.

Email: aizat.azmi.1987@gmail.com

\section{INTRODUCTION}

Nowadays, the demand for electrical power supply around the world has increased tremendously as all sectors in every country depend strongly on power supply in order to fulfill their needs. Hence, manufacturers related to electrical power industry, especially producers of high voltage cables, have an important responsibility to ensure that their cables can address the increased power demand. This leads to the need of more advanced electrical insulation, which is expected to have better endurance and reliability than conventional insulation systems [1-3].

Polymer nanocomposites' use in electrical insulation was introduced in 1990s by Lewis [4]. The idea behind this is to combine polymers with a few weight percent (wt\%) of nanometer-sized fillers under homogeneous mixing. In this, the physical, chemical and electrical properties of nanocomposites were found to be better than the unfilled polymers.

Cross-linked polyethylene (XLPE) has been widely used as high voltage AC (HVAC) and high voltage DC (HVDC) cable insulation [5-7]. Nevertheless, many studies reported the drawbacks of XLPE, such as its difficulty to recycle, increased space charge accumulation, and poor long-term deterioration properties [1]. Polypropylene (PP) material has a potential to replace XLPE cables. PP has been reported to have higher melting temperature than XLPE (commonly above $150^{\circ} \mathrm{C}$ ) [8-9]. Besides that, PP exhibits high mechanical strength [10-11] and low dielectric constant [12]. Furthermore, PP possesses good charactistics as high voltage cable insulation as it has reduced space charge accumulation [13], high volume resistivity [14], and high breakdown strength [15-17] compared with XLPE. 
Previous research on nanocomposites in electrical insulation mostly focused on single-metal oxide nanofillers suh as magnesium oxide $(\mathrm{MgO})$, titanium dioxide $(\mathrm{TiO} 2)$, zinc oxide $(\mathrm{ZnO})$, and aluminum oxide (A12O3) [18-20] as nanofillers. Meanwhile, the use of multi-element oxide nanofillers, from the perspective of dielectric, has been less explored. Hence, it is important to investigate the effect of different types of multi-element oxide nanofillers on the dielectric properties of PP nanocomposites. The results are useful to guide the development of potentially recyclable HVDC and HVAC cable insulation materials.

Therefore, this research aimed to investigate the breakdown characteristics (i.e., AC and DC breakdown) and chemical structure of PP containing $\mathrm{CaCO} 3$ nanofiller (also known as $\mathrm{PP} / \mathrm{CaCO} 3$ nanocomposites). The use of $\mathrm{CaCO}_{3}$ as an alternative inorganic filler in PP will contribute to further understanding of the effects of using multi-element oxide nanofillers for cable insulation applications.

\section{RESEARCH METHOD}

\subsection{Sample preparation}

PP used in this study composed of 50\% of PP homopolymer and 50\% of PP impact copolymer, which were obtained from Lotte Chemical Titan, with manufacturer codes of TITANPRO 6531M and TITANPRO SM340, respectively. Besides that, $\mathrm{CaCO}_{3}$ nanofiller, which was obtained from the SkySpring Nanomaterials, was used. The nanofiller had a particle size ranging from 15 to $40 \mathrm{~nm}$. Nanofiller concentration level of $5 \mathrm{wt} \%$ was chosen. Brabender melt mixer was used for sample preparation. The rotational speed was set to $50 \mathrm{rpm}$. Meanwhile, a temperature of $180^{\circ} \mathrm{C}$ was used throughout the mixing process. The complete mixing duration was set to $10 \mathrm{~min}$. Next, a hydraulic laboratory press was employed to produce disc-shaped sample films. In this, the processing temperature and pressure were set to $180^{\circ} \mathrm{C}$ and 3 tons, respectively. Next, the samples were cool down naturally under laboratory ambient environment. Figure 1 and Figure 2 demonstrate an example of a PP compound produced from the Brabender melt mixer and a disc-shaped PP sample produced from the hydraulic laboratory press, respectively.

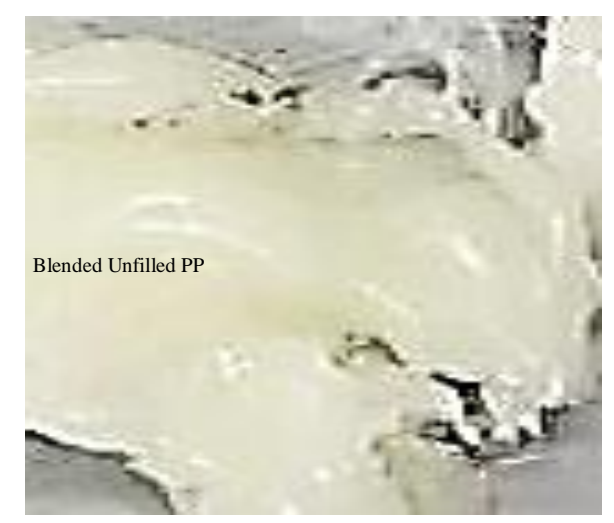

Figure 1. Polypropylene sample prepared by means of Brabender melt mixer

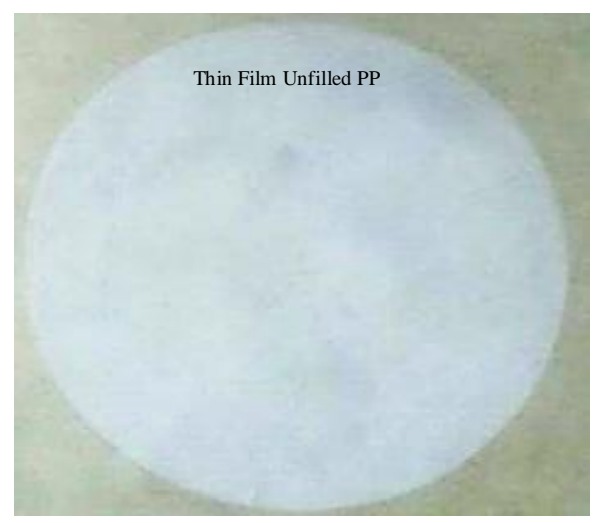

Figure 2. Polypropylene sample prepared by means of hydraulic laboratory press

\subsection{Breakdown testing}

$\mathrm{AC}$ and DC breakdown tests were carried out by means of a dielectric strength tester. The tests were done in accordance with the guidelines laid out in the American Society for Testing and Materials (ASTM) D149. Each sample, with $100 \mu \mathrm{m}$ of thickness, was used for these tests. The sample was placed between two sphere electrodes. Besides that, the sample was immersed in mineral oil in order to prevent surface discharges. The breakdown strength test was conducted by applying a step voltage of $1 \mathrm{kV}$ every $20 \mathrm{~s}$ for AC breakdown tests. The voltage was increased until the sample experienced breakdown. Meanwhile, a step voltage of $2 \mathrm{kV}$ every $20 \mathrm{~s}$ was used for DC breakdown tests. Similarly, the voltage was increased until the occurance of breakdown. The breakdown readings were recorded and analyzed by using the two-parameter Weibull distribution analysis. As shown in (1) and (2) represent the dielectric breakdown strength and Bernard's approximation, respectively. Meanwhile, As shown in (3) shows the probability of breakdown strength by means of cumulative distribution function (CDF) through Weibull distribution analysis.

$$
\text { BreakdownStrength }\left(\frac{\mathrm{kV}}{\mathrm{mm}}\right)=\frac{\text { BreakdownVoltage }(\mathrm{kV})}{\text { SpecimenThickness }(\mathrm{mm})}
$$




$$
\begin{aligned}
& F(i, N)=\frac{i-0.3}{N+0.4} \\
& F\left(E_{b d} ; \alpha, \beta\right)=1-\exp \left[-\left(\frac{E_{b d}}{\alpha}\right)^{\beta}\right]
\end{aligned}
$$

Based on (2), $i$ represents the sequence of dielectric breakdown strength. Meanwhile, $N$ is the total number of breakdown tests. Based on (3), the probability of dielectric breakdown strength of the specimen is represented as $F\left(E_{b d} ; \alpha, \beta\right)$, where $\alpha$ is the scale parameter and $\beta$ is the shape parameter based on the Weibull analysis.

\subsection{Fourier transform infrared analysis}

Fourier transform infrared (FTIR) spectroscopy was used to obtain the chemical information pertaining to the prepared nanocomposites. The FTIR machine model IRTracer-100 from SHIMADZU was used. The spectral data were collected from $600 \mathrm{~cm}^{-1}$ to $4000 \mathrm{~cm}^{-1}$ over 8 scans. For this analysis, sample with $100 \mu \mathrm{m}$ of thickness was used.

\subsection{Morphological characterization}

Morphological characterization of PP nanocomposites containing $\mathrm{CaCO}_{3}$ was carried out to analyse the dispersion state of $\mathrm{CaCO}_{3}$ nanoparticles in PP using Hitachi TM3000. Generally, a $15 \mathrm{kV}$ voltage at 38 $\mathrm{mm}$ distance was applied during the characterization. Prior to SEM, the samples were immersed in liquid nitrogen and fractured. The fracture surfaces of the samples were then sputter coated with platinum to minimize charge accumulation and poor resolution during morphological inspections.

\section{RESULTS AND DISCUSSION}

\subsection{Breakdown results}

Figures 3(a) and 3(b) desmonstrate the $\mathrm{AC}$ and $\mathrm{DC}$ breakdown strength of unfilled PP and PP nanocomposites, respectively; the Weibull data are listed in Table 1. It should be noted that the scale parameter $\alpha$ represents the breakdown strength while the shape parameter $\beta$ represents the reliability of the Weibull distribution.

Clearly, these unfilled PP and PP nanocomposite samples behaved differently under AC and DC applied fields. It can be noted that the unfilled PP had higher AC and DC breakdown strength than that of $\mathrm{PP} / \mathrm{CaCO} 3$ nanocomposites, with $112 \mathrm{kV}$ mm-1 and $323 \mathrm{kV} \mathrm{mm}-1$, respectively. Meanwhile, PP/CaCO3 nanocomposites had the AC and DC breakdown strength of $96 \mathrm{kV} \mathrm{mm} \mathrm{mm}^{-1}$ and $257 \mathrm{kV} \mathrm{mm}^{-1}$, respectively. These results show that the breakdown strength of $\mathrm{PP} / \mathrm{CaCO}_{3}$ nanocomposites under $\mathrm{AC}$ and $\mathrm{DC}$ applied fields was lower compared with unfilled PP. These results are in line with the research in [21-24].

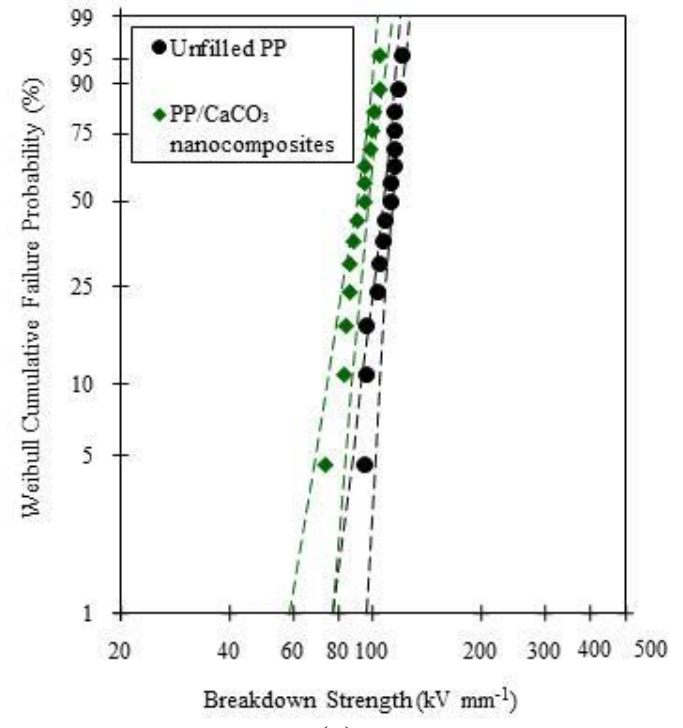

(a)

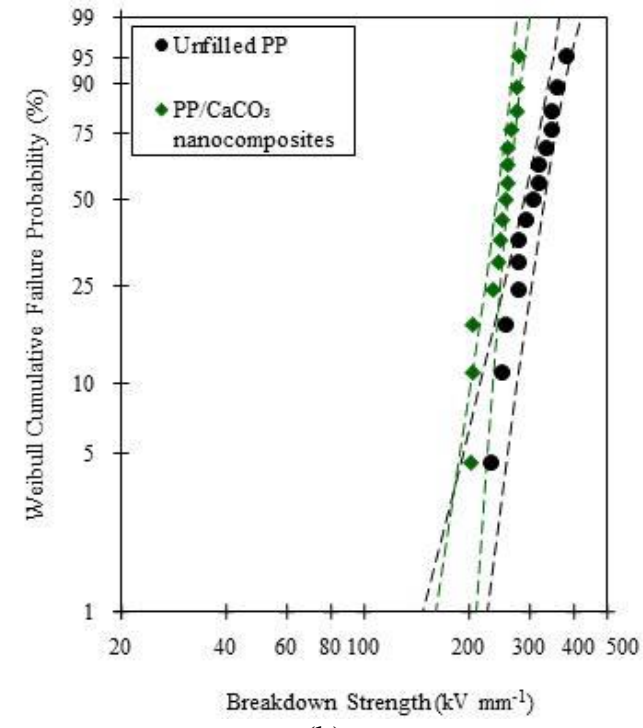

(b)

Figure 3. Weibull plots for comparing (a) AC and (b) DC breakdown strength of unfilled PP and $\mathrm{PP} / \mathrm{CaCO}_{3}$ nanocomposites 


\begin{tabular}{cccc}
\multicolumn{4}{c}{ Table 1. Weibull distribution parameters } \\
\hline Breakdown & Sample & $\alpha\left(\mathrm{kVmm}^{-1}\right)$ & $\beta$ \\
\hline AC & Unfilled PP & $112 \pm 3$ & $17 \pm 8$ \\
AC & PP/CaCO & $96 \pm 4$ & $13 \pm 5$ \\
DC & Unfilled PP & $323 \pm 18$ & $8 \pm 3$ \\
DC & $\mathrm{PP} / C a C O_{3}$ & $257 \pm 9$ & $14 \pm 5$ \\
\hline
\end{tabular}

\subsection{Fourier transform infrared spactra}

Figure 4 illustrates the FTIR spectra of unfilled PP and PP nanocomposites. As a reference, the characteristic absorption bands for the unfilled PP are $2950 \mathrm{~cm}^{-1}, 2836 \mathrm{~cm}^{-1}, 1458 \mathrm{~cm}^{-1}, 1378 \mathrm{~cm}^{-1} ; 1170 \mathrm{~cm}^{-1}$ and $844 \mathrm{~cm}^{-1}$. These FTIR values of PP are in line with the values reported in the literature [25]. Besides that, the characteristic absorption bands at $873 \mathrm{~cm}^{-1}$ and $707 \mathrm{~cm}^{-1}$ of $\mathrm{PP} / \mathrm{CaCO}_{3}$ nanocomposites are indicative of fundamental band of calcite and asymmetrical stretching vibration peaks of $\mathrm{Ca}-\mathrm{O}$ [26]. It can be concluded that the $\mathrm{CaCO}_{3}$ nanofiller was successfully attached in PP polymer as demonstrated in the FTIR analysis.

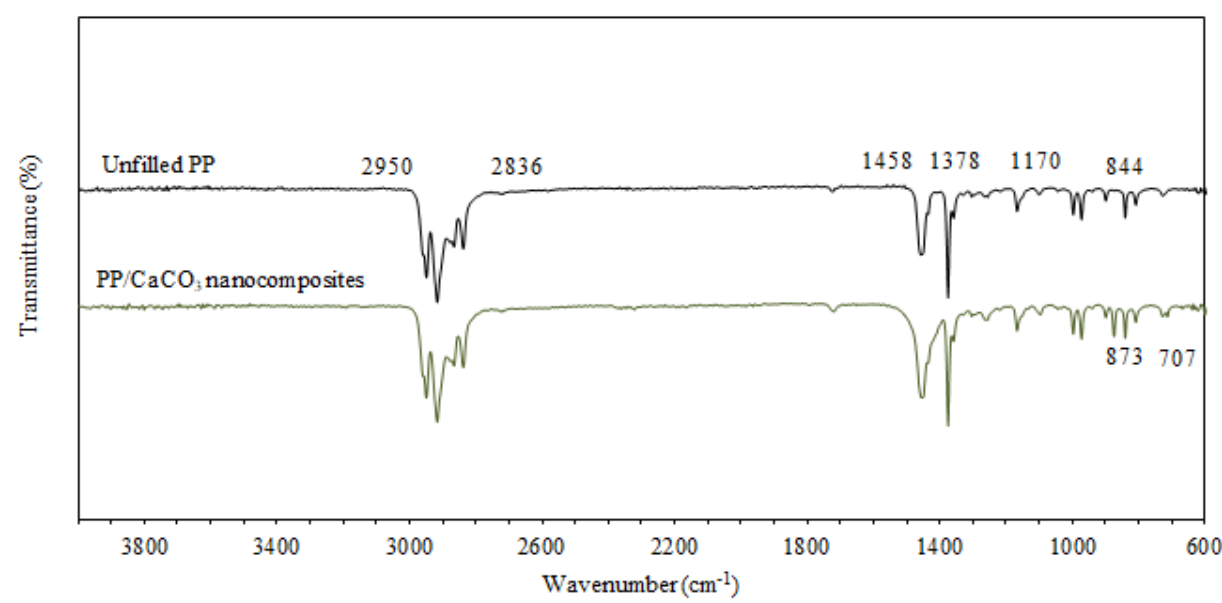

Figure 4. FTIR spectra comparing unfilled $\mathrm{PP}$ and $\mathrm{PP} / \mathrm{CaCO}_{3}$ nanocomposites

\subsection{Morphology}

Figures 5(a) and 5(b) show the SEM micrograph obtained from unfilled PP and $\mathrm{PP} / \mathrm{CaCO}_{3}$ nanocomposites. The SEM micrograph of unfilled PP reveals some degree of the structure of PP blends, but the detailed structure and morphology of the unfilled PP is not well revealed in this fracture surface. Meanwhile, there are several $\mathrm{CaCO} 3$ nanoparticles of about $100 \mathrm{~nm}$ in size that could be observed as indicated by the arrows in Figure 5(b). However, the agglomeration of $\mathrm{CaCO} 3$ nanoparticles could also be observed as indicated by the circles. It was expected that, agglomeration would lead to reduced breakdown strength. Nevertheless, an alternative $\mathrm{CaCO}_{3}$ nanofiller, such as surface modified $\mathrm{CaCO}_{3}$ nanofiller, could be explored to improve the dispersion the nanoparticles across the samples in an attempt to improve the breakdown performance.

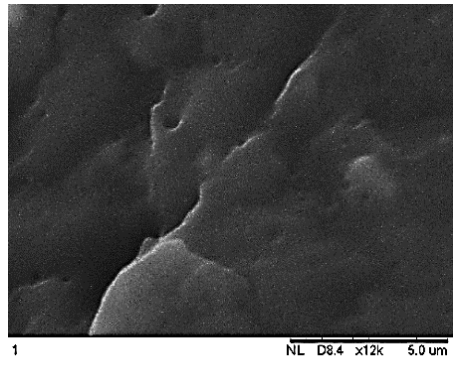

(a)

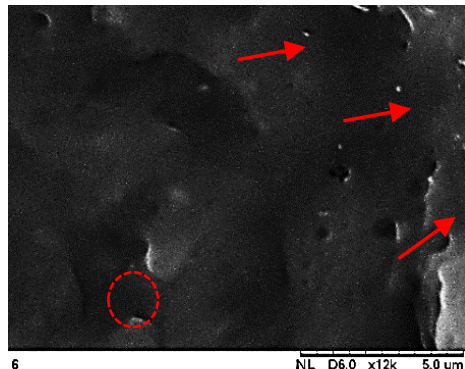

(b)

Figure 5. SEM micrograph of (a) unfilled $\mathrm{PP}$ and (b) $\mathrm{PP} / \mathrm{CaCO}_{3}$ nanocomposites 


\section{CONCLUSIONS}

This research was conducted to investigate the breakdown characteristics (i.e., AC and DC breakdown) and chemical structure of unfilled $\mathrm{PP}$ and $\mathrm{PP} / \mathrm{CaCO}_{3}$ nanocomposites. It can be concluded that, the $\mathrm{CaCO}_{3}$ nanofiller was successfully attached to PP polymer as demonstrated in the FTIR analysis. Besides that, the breakdown strength of $\mathrm{PP} / \mathrm{CaCO}_{3}$ nanocomposites under $\mathrm{AC}$ and $\mathrm{DC}$ applied fields was lower compared with unfilled PP. This was due to the agglomeration of $\mathrm{CaCO}_{3}$, which in turns reduced the breakdown performances.

\section{ACKNOWLEDGEMENTS}

The authors thank Malaysia Ministry of Education, Universiti Teknologi Malaysia, and Nippon Sheet Glass Foundation for Materials Science and Engineering for financial sponsorship and the respective FRGS (FRGS/1/2019/TK04/UTM/02/1), RUG (16J55), and NSG (4B373) research grants. Scholarship from UTM Zamalah PhD is also acknowledged.

\section{REFERENCES}

[1] T. Andritsch, A. Vaughan, and G. C. Stevens, "Novel Insulation Materials for High Voltage Cable Systems," IEEE Electr. Insul. Mag., vol. 33, no. 4, pp. 27-33, 2017.

[2] X. Huang, Y. Fan, J. Zhang, and P. Jiang, "Polypropylene Based Thermoplastic Polymers for Potential Recyclable HVDC Cable Insulation Applications,” IEEE Trans. Dielectr. Electr. Insul., vol. 24, no. 3, pp. 1446-1456, 2017.

[3] Y. Jung, B. Lee, I. Seo, J. Kwon, K. Sohn, and H. Kim, "Development Status of MV Cable with Eco-friendly and High Heat Resistance," KEPCO J. Electr. Power Energy, vol. 2, no. 1, pp. 55-60, 2016.

[4] T. J. Lewis, "Nanometric Dielectrics," J. Phys. D. Appl. Phys., vol. 38, no. 2, pp. 202-212, 2005.

[5] X. Qi and S. Boggs, "Thermal and Mechanical Properties of EPR and XLPE Cable Compounds," IEEE Electr. Insul. Mag., vol. 22, no. 3, pp. 19-24, 2006.

[6] L. Boukezzi, A. Boubakeur, and M. Lallouani, "Effect of artificial thermal aging on the crystallinity of XLPE insulation cables: X-ray study," in Annual Report - Conference on Electrical Insulation and Dielectric Phenomena, CEIDP, 2007, pp. 65-68.

[7] W. Lei, K. Wu, Y. Wang, Y. Cheng, X. Zheng, L. A. Dlssado, S. J. Dodd, N. M. Chalashkanov, J. C. Fothergill, C. Zhang, and W. Li, "Are nano-composites really better DC insulators? A study using silica nanoparticles in XLPE," IEEE Trans. Dielectr. Electr. Insul., vol. 24, no. 4, pp. 2268-2270, 2017.

[8] W. Cheewawuttipong, D. Fuoka, S. Tanoue, H. Uematsu, and Y. Iemoto, "Thermal and Mechanical Properties of Polypropylene/Boron Nitride Composites,” Energy Procedia, vol. 34, pp. 808-817, 2013.

[9] W. Cao, Z. Li, G. Sheng, and X. Jiang, "Insulating property of polypropylene nanocomposites filled with nano$\mathrm{MgO}$ of different concentration," IEEE Trans. Dielectr. Electr. Insul., vol. 24, no. 3, pp. 1430-1437, 2017.

[10] D. Eiras and L. A. Pessan, "Mechanical Properties of Polypropylene/Calcium Carbonate Nanocomposites," Mater. Res., vol. 12, no. 4, pp. 517-522, 2009.

[11] Y. Lin, H. Chen, C. Chan, and J. Wu, "The Toughening Mechanism of Polypropylene/Calcium Carbonate Nanocomposites," Polymer (Guildf)., vol. 51, no. 14, pp. 3277-3284, 2010.

[12] S. Virtanen, H. Ranta, S. Ahonen, M. Karttunen, J. Pelto, K. Kannus, and M. Pettersson, "Structure and dielectric breakdown strength of nano calcium carbonate/polypropylene composites," J. Appl. Polym. Sci., vol. 131, no. 1, pp. 39504-39504, 2014.

[13] Y. Zhou, J. Hu, B. Dang, and J. He, "Mechanism of Highly Improved Electrical Properties in Polypropylene by Chemical Modification of Grafting Maleic Anhydride," J. Phys. D. Appl. Phys., vol. 49, no. 41, 2016.

[14] Y. Zhou, J. Hu, X. Chen, F. Yu, and J. He, "Thermoplastic Polypropylene/Aluminum Nitride Nanocomposites with Enhanced Thermal Conductivity and Low Dielectric Loss," IEEE Trans. Dielectr. Electr. Insul., vol. 23, no. 5, pp. 2768-2776, 2016.

[15] I. L. Hosier, A. S. Vaughan, A. Pye, and G. C. Stevens, "High performance polymer blend systems for HVDC applications," IEEE Trans. Dielectr. Electr. Insul., vol. 26, no. 4, pp. 1197-12013, 2019.

[16] Y. Zhou, J. Hu, B. Dang, and J. He, "Effect of different nanoparticles on tuning electrical properties of polypropylene nanocomposites," IEEE Trans. Dielectr. Electr. Insul., vol. 24, no. 3, pp. 1380-1389, 2017.

[17] H. Mao, B. He, W. Guo, L. Hua, and Q. Yang, "Effects of nano-CaCO3 content on the crystallization, mechanical properties, and cell structure of pp nanocomposites in microcellular injection molding," Polymer (Guildf)., vol. 10, no. 10 , pp. $1-18,2018$.

[18] C. Q. Li, J. W. Zha, H. Q. Long, S. J. Wang, D. L. Zhang, and Z. M. Dang, "Mechanical and dielectric properties of graphene incorporated polypropylene nanocomposites using polypropylene-graft-maleic anhydride as a compatibilizer," Compos. Sci. Technol., vol. 153, pp. 111-118, 2017.

[19] J. Zha, Q. Qin, and Z. Dang, "Effect of multi-dimensional zinc oxide on electrical properties of polypropylene nanocomposites for HVDC cables," IEEE Trans. Dielectr. Electr. Insul., vol. 26, no. 3, pp. 868-875, 2019.

[20] I. Rytöluoto, K. Lahti, and F.- Tampere, "Large-area dielectric breakdown performance of polymer films - part II: interdependence of filler content, processing and breakdown performance in polypropylene-silica nanocomposites," IEEE Trans. Dielectr. Electr. Insul., vol. 22, no. 4, pp. 2196-2206, 2015. 
[21] N. H. Rahim, K. Y. Lau, N. A. Muhamad, N. Mohamad, W. A. W. A. Rahman, and A. S. Vaughan, "Effects of filler calcination on structure and dielectric properties of polyethylene/silica nanocomposites," IEEE Trans. Dielectr. Electr. Insul., vol. 26, no. 1, pp. 284-291, 2019.

[22] K. Lau, A. Vaughan, G. Chen, I. Hosier, A. Holt, and K. Ching, "On the Space Charge and DC Breakdown Behavior of Polyethylene/Silica Nanocomposites," IEEE Trans. Dielectr. Electr. Insul., vol. 21, no. 1, pp. 340-351, 2014.

[23] S. N. H. Kamarudin, K. Y. Lau, and W. A. W. A. Rahman, "The Effect of Non-Isothermal Crystallization on the AC Breakdown Performance of Polyethylene/Silicon Dioxide Nanocomposites," in IEEE Conference on Energy Conversion (CENCON), pp. 7-10, 2017.

[24] Y. Zhou, J. Hu, B. Dang, and J. He, "Effect of Different Nanoparticles on Tuning Electrical Properties of Polypropylene Nanocomposites," IEEE Trans. Dielectr. Electr. Insul., vol. 24, no. 3, pp. 1380-1389, 2017.

[25] C. Xiaohong, W. Weiwang, L. Shengtao, F. Michel, and Z. Xiaohong, "Polymer nanocomposites in high-voltage insulation," IEEE Nanotechnol. Mag., no. june, pp. 33-40, 2018.

[26] S. Abdolmohammadi, S. Siyamak, N. A. Ibrahim, W. Zin, and W. Yunus, "Enhancement of mechanical and thermal properties of polycaprolactone/chitosan blend by calcium carbonate nanoparticles," Int. J. Mol. Sci., vol. 13, pp. 4508-4522, 2012.

\section{BIOGRAPHIES OF AUTHORS}

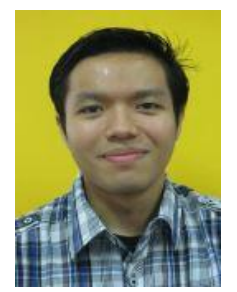

Aizat Azmi received the B.Eng. degree in Electrical (Control and Instrumentation) and the M.Eng. degree in Electrical Engineering from Universiti Teknologi Malaysia (UTM), Johor Bahru, Malaysia, in 2011 and 2014, respectively. He is currently a $\mathrm{PhD}$ candidate at High Voltage and High Current (IVAT) Universiti Teknologi Malaysia. His research interests are in field of high voltage cable insulation and sensor technology.

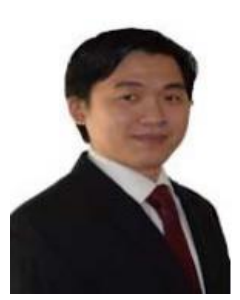

Kwan Yiew Lau received his B.Eng. degree in Electrical Engineering with First Class Honors from Universiti Teknologi Malaysia in 2007. After working as an Electronics Development Engineer at Dyson Malaysia, he joined Universiti Teknologi Malaysia as a Tutor in 2008. He then completed his MEng degree in Electrical Power Engineering at the same university in 2010. Later in 2013, he received his Ph.D. degree in Electronics and Electrical Engineering from the University of Southampton, UK. He is now a Senior Lecturer at the Institute of High Voltage and High Current, Universiti Teknologi Malaysia. He is also a Chartered Engineer of the Engineering Council UK, a Professional Engineer of the Board of Engineers Malaysia, and the Past Chair of the IEEE Dielectrics and Electrical Insulation Society (DEIS) Malaysia.

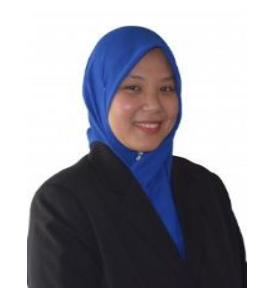

Noor Azlinda Ahmad received her B.Eng. (Electrical) and M. Eng. (Electrical) Degree from Universiti Teknologi Malaysia in 2001 and 2003, respectively. She completed her $\mathrm{PhD}$ in Atmospheric Discharge from Uppsala University, Sweden in 2011. At present she is a senior lecturer at Institute of High Voltage and High Current (IVAT) Universiti Teknologi Malaysia. Her major research interests are lightning protection, measurement, detection and characterization.

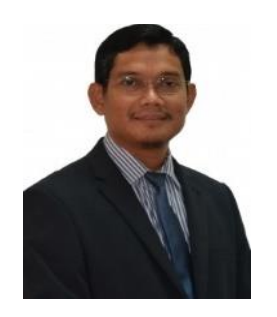

Zulkurnain Abdul-Malek (M'03) received the B.E. degree in electrical and computer systems from Monash University, Melbourne, Australia, in 1989, the M.Sc. degree in electrical and electromagnetic engineering with industrial applications from the University of Wales Cardiff, U.K., in 1995 and the Ph.D. degree in high voltage engineering from Cardiff University, U.K., in 1999. He has been with Universiti Teknologi Malaysia (UTM) for 30 years, and he is currently a Professor of High Voltage Engineering with the Faculty of Engineering, and the Director of the Institute of High Voltage and High Current (IVAT), UTM.

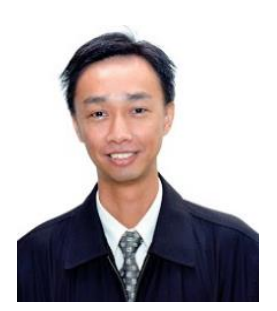

Chee Wei Tan (M'11-SM'17) received the B.Eng. degree in electrical engineering (First Class Honors) from Universiti Teknologi Malaysia (UTM), Johor, Malaysia, in 2003, and the Ph.D. degree in electrical engineering from Imperial College London, London, U.K., in 2008. He is an Associate Professor with UTM and a Member of the Power Electronics and Drives Research Group, School of Electrical Engineering, Faculty of Engineering, UTM. He is also a Chartered Engineer registered with the Engineering Council, U.K. and a Professional Engineer registered with the Board of Engineers Malaysia. He is an active participant of IEEE activities and conferences. His research interests include the application of power electronics in renewable/alternative energy systems, control of power electronics and energy management systems in microgrids. 